Tersedia online di http://ejournal.undip.ac.id/index.php/kiryoku

\title{
Makna Verba Bahasa Jepang “Tsukuru” Dan Bahasa Indonesia "Membuat"
}

\author{
Sriwahyu Istana Trahutami, Nikolaus Caesar Richard Lee \\ Universitas Diponegoro \\ sriwahyuistanatrahut@lecturer.undip.ac.id \\ ncrichardlee@students.undip.ac.id
}

\begin{abstract}
Abstrak
(Verba Bermakna "Membuat" Dalam Bahasa Jepang dan Bahasa Indonesia). Jumlah kosa kata bahasa Jepang yang jauh lebih banyak daripada Bahasa Indonesia sering menimbulkan masalah pada waktu belajar bahasa Jepang. Salah satu kesulitan yang sering dihadapi adalah memahami makna dan mencari padanannya dalam bahasa Indonesia. Tujuan penulisan artikel ini adalah untuk mendeskripsikan makna verba tsukuru dalam bahasa Jepang, serta verba membuat dalam bahasa Indonesia sekaligus mencari persamaan dan perbedaan makna kedua verba tersebut. Data penelitian diperoleh dari artikel dan website. Metode deskriptif kualitatif digunakan untuk menganalisis data kalimat Bahasa Jepang dan Bahasa Indonesia, dilanjutkan dengan menganalisis persamaan dan perbedaan maknanya melalui perbandingan (kontrastif). Berdasarkan hasil analisis disimpulkan bahwa kedua verba berfungsi sebagai predikat dalam kalimat transitif. Keduanya juga merupakan polisemi dengan makna dasar menciptakan benda atau hal yang belum ada sebelumnya, menggunakan kemampuan yang dimiliki oleh pembuat. Sementara perbedaannya, verba membuat dalam bahasa Indonesia juga mempunyai makna menyebabkan. Sedangkan dalam bahasa Jepang verba tsukuru selain bermakna membuat juga mempunyai makna memelihara, merawat, mendidik. Selain itu ada tiga penulisan huruf yang berbeda untuk verba tsukuru, yang masing-masing mempunyai pasangan objek berbeda pula.
\end{abstract}

\section{Kata kunci: kontrastif, membuat, tsukuru, verba}

\section{ABSTRACT}

(Verb Means "to make" in Japanese and Indonesian). The number of Japanese vocabularies which is much more than Indonesian often causes problems when learning Japanese. One of the difficulties that are often faced is understanding the meaning and finding its equivalent in Indonesian. The purpose of writing this article is to describe the meaning of the verb tsukuru in Japanese, and the verb to make in Indonesian, while looking for similarities and differences in the meanings of the two verbs. Research data obtained from articles and websites. Qualitative descriptive method was used to analyze the data of Japanese and Indonesian sentences, followed by analyzing the similarities and differences in their meanings through comparisons (contrastive). Based on the results of the analysis, it is concluded that both verbs function as predicates in transitive sentences. Both are also polysemy with the basic meaning of creating objects or things that did not exist before, using the abilities possessed by the maker. While the difference is, the verb to make in Indonesian also has the meaning of causing. Meanwhile, in Japanese, the verb tsukuru means not only to make, but also to maintain, to care for, to educate. In addition, there are three different letters for the verb tsukuru, each of which has a different pair of objects. 
Tersedia online di http://ejournal.undip.ac.id/index.php/kiryoku

Keywords: contrastive, make, tsukuru, verb

\section{PENDAHULUAN}

Dalam proses pembelajaran bahasa asing, pemahaman terhadap makna kosa kata menjadi hal yang mutlak, sekaligus sering menjadi persoalan tersendiri untuk pembelajar. Hal ini terjadi dalam pembelajaran bahasa apapun, termasuk bahasa Jepang. Bahasa Jepang mempunyai kosa kata yang jauh lebih banyak dibandingkan dengan bahasa Indonesia, sehingga seringkali satu kosa kata dalam bahasa Indonesia, ketika diterjemahkan ke dalam bahasa Jepang bisa dimunculkan dalam beberapa kosa kata, tergantung makna dan konteks yang menyertainya. Satu karakter huruf kanji bisa dibaca dengan cara baca Jepang, cara baca China, tergantung huruf lain yang menyertainya.

Verba tsukuru (作る) yang termasuk ke dalam polisemi / tagigo mempunyai beberapa makna, dengan makna dasarnya "membuat". Namun makna "membuat" ini bukan hanya ditemukan pada kata tsukuru yang ditulis dengan huruf kanji 作る saja. Setidaknya terdapat juga huruf kanji 造 る, dan 創る yang dibaca tsukuru juga, dan mempunyai makna membuat. Ketiga verba ini pada satu kamus dimasukkan dalam entri yang sama, namun pada kamus yang lainnya ada yang memasukkan dalam entri yang berbeda. Ketiga verba tsukuru dengan huruf kanji berbeda tersebut, meskipun mempunyai makna yang sama, yaitu membuat, namun masing-masing mempunyai ciri, dengan nomina apa verba tsukuru tersebut bisa dipasangkan. Contoh di atas sebagai salah satu gambaran rumitnya mempelajari makna dalam bahasa Jepang.

Sementara di dalam bahasa Indonesia, pada Kamus Besar Bahasa Indonesia, verba "membuat" juga mempunyai beberapa makna, seperti menciptakan, melakukan atau mengerjakan, menggunakan; memakai, dan menyebabkan.
Artikel ini akan mendeskripsikan bagaimana makna kata membuat baik dalam bahasa Indonesia maupun bahasa Jepang, berikut persamaan dan perbedaannya. Melalui deskripsi ini diharapkan pembelajar bahasa Jepang yang mempunyai bahasa ibu Bahasa Indonesia, lebih mudah memahami bagaimana sebenarnya makna tsukuru, sekaligus dapat membandingkan dengan makna membuat dalam bahasa Indonesia.

Jurnal maupun skripsi yang telah membahas relasi makna verba tsukuru ini, antara lain, penelitian yang dilakukan oleh Puspita Reny (2013) dengan judul "Analisis Verba Tsukuru dalam Bahasa Jepang”, yang membahas tentang bagaimana pengklasifikasian makna verba tsukuru dalam kalimat bahasa Jepang. Dengan pendekatan deskriptif kualitatif, penelitian ini menganalisis kalimat yang mengandung verba tsukuru berdasarkan makna semantisnya. Dari hasil penelitian tersebut diketahui beberapa makna dari verba tsukuru yaitu yang pertama "menghasilkan sesuatu baru yang berbeda", menciptakan sesuatu atau hal yang baru atau hal yang dulunya sudah ada tetapi terjadi perbedaan hasil antara yang dulu dengan hasil yang sekarang, sehingga menjadi suatu hal yang bisa dianggap baru. Kemudian yang kedua, makna verba tsukuru yang berarti "mengadakan sesuatu yang tidak ada". Dan yang terakhir makna verba tsukuru bermakna "berseru; menginformasikan atau melaporkan".

\section{METODE}

Penelitian ini menggunakan metode deskriptif kualitatif, dengan pendekatan kontrastif, dimana analisis kualitatif berfokus pada penunjukkan makna, deskripsi, penjernihan, dan penempatan 
data pada konteksnya masing-masing (Mahsun, 2006:233). Sementara itu pendekatan kontrastif adalah kegiatan memperbandingkan struktur bahasa pertama (B1) dengan dan bahasa kedua (B2) untuk mengidentifikasi kedua bahasa tersebut (Tarigan, 1990:2). Menurut Ishiwata (1995:9) analisis kontrastif adalah kajian bahasa yang membahas bunyi, kosa kata, tata bahasa dan lain-lain dalam dua bahasa atau lebih, kemudian dibandingkan bagian dari berbagai aktifitas kebahasaan untuk mendefinisikan dengan jelas bagian mana yang sama atau tidak secara jelas. Pendekatan kontrastif yang digunakan dalam penelitian ini berguna untuk mencari keunikan, ciri khas yang terdapat pada makna masing-masing kata dengan menitik beratkan pada perbedaan dan persamaan melalui fakta kebahasaan yang konkrit dalam hal ini melalui data kalimat-kalimat yang dianalisis.

Data yang digunakan pada penelitian ini adalah kalimat-kalimat berbahasa Jepang atau reibun yang berasal dari berbagai sumber seperti media massa eletronik www.asahi.com, ejje.weblio.com, www.yomiuri.co.jp dan sebagainya untuk data berbahasa Jepang, sedangkan data kalimat berbahasa Indonesia, diperoleh dari media massa eletronik www.kompas.com, dan mediaindonesia.com. Teknik catat melalui pengkartuan sederhana digunakan untuk menerjemahkan, kemudian mengklasifikasikan data berdasarkan makna. Kemudian analisis data masingmasing kalimat dilakukan melalui pendeskripsian secara detil tentang makna tsukuru melalui huruf kanji sebagai simbolnya, kemudian dibandingkan dengan makna membuat dalam bahasa Indonesia, sehingga diperoleh simpulan tentang bagaimana perbedaan dan persamaan makna kedua verba tersebut dalam bahasa Indonesia maupun dalam bahasa Jepang.

\section{HASIL DAN PEMBAHASAN}

\section{Verba Tsukuru}

Verba tsukuru maupun membuat, keduanya merupakan verba transitif atau tadoushi yang berfungsi sebagai pengisi predikat dalam kalimat. Di dalam struktur bahasa Jepang, predikat diletakkan di bagian akhir kalimat, dapat dikatakan mempunyai susunan terbalik dengan struktur pola kalimat bahasa Indonesia.

Verba transitif atau yang disebut tadoushi dalam bahasa Jepang merupakan verba yang memerlukan nomina sebagai objek dalam kalimat aktif, dan objek itu dapat berfungsi sebagai subjek dalam kalimat pasif. Tadoushi tidak hanya menerangkan perubahan, melainkan juga menekankan pada proses atau aktivitas yang menyebabkan perubahan tersebut (Iori, 2001: 148). Tadoushi ditandai dengan partikel wo untuk menyatakan objek dari verba tersebut.

Menurut penggolongan jenis verba bahasa Jepang, tsukuru masuk dalam golongan godan doushi atau verba kelompok satu. Sedangkan dilihat dari relasi makna verba tsukuru termasuk polisemi, yaitu satu kata yang mempunyai lebih dari satu makna. Polisemi didaftarkan sebagai sebuah entri dalam kamus. Perbedaan antara polisemi dan homonim, pada homonim maknamakna pada masing-masing kata tidak ada kaitan atau hubungan sama sekali antara yang satu dengan yang lain. Sedangkan pada polisemi, makna-makna pada kata yang berpolisemi masih ada hubungannya karena memang dikembangkan dari komponen - komponen makna kata - kata tersebut.

Dari referensi berbagai kamus diketahui bahwa verba tsukuru mempunyai makna : 
A. Memberdayakan kemampuan untuk menciptakan sesuatu. Contoh : tsukue wo tsukuru, ie wo tsukuru

B. Menciptakan hasil karya seni / sastra. Contoh : shi wo tsukuru, waka wo tsukuru.

C. Mengolah perkebunan / sawah, bercocok tanam, contoh : hatake wo tsukuru, yasai wo tsukuru.

D. Menciptakan sesuatu / hal yang baru yang tidak ada sebelumnya, mendirikan. Contoh : kodomo wo tsukuru, shiten wo tsukuru.

E. Memasak, menciptakan masakan. Contoh : ryouri wo tsukuru, gohan wo tsukuru.

F. Berhias, mempercantik diri. Contoh : kao wo tsukuru、 uwabe wo tsukuru.

G. Meniru, berpura pura, bohong Contoh : koe wo tsukuru, nakigoe wo tsukuru.

H. Mengerjakan, melakukan sesuatu. Contoh : tsumi wo tsukuru.

Jika dilihat dari penulisan, terdapat beberapa penulisan tsukuru, dengan simbol huruf kanji yang berbeda, meskipun cara bacanya sama, yaitu 作る、造る、dan 創 る. Dari beberapa kamus diketahui ada yang masuk dalam satu entri namun juga ada yang memasukkan dalam entri yang berbeda seperti pada kamus Kadokawa Kokugo Jiten. Dalam kamus ini ketiga kata tersebut masuk dalam entri berbeda, masing-masing berdiri sebagai sebuah kata. Yang paling umum digunakan adalah tsukuru dengan huruf kanji 作る. Kata 作 る dan 造る mempunyai fitur kesamaan makna koshiraeru 'membuat'. Tsukuru dengan huruf kanji 作る, biasa digunakan untuk menyatakan makna membuat sesuatu yang kecil atau dalam skala kecil, seperti pada ryouri wo tsukuru 'membuat masakan', dan 'moukei wo tsukuru 'membuat model / contoh produk'. Juga digunakan untuk objek yang tidak mempunyai bentuk atau abstrak, misalnya kiroku wo tsukuru 'membuat catatan'dan omoide wo tsukuru 'membuat kenangan'.

Verba 造る, mempunyai ciri digunakan untuk objek yang mempunyai bentuk dan berukuran besar, seperti pada biru wo tsukuru 'membuat gedung' dan fune wo tsukuru 'membuat kapal'. Selain itu membuat sake (beer Jepang), miso (bahan yang digunakan untuk membuat sup Jepang), shoyu (kecap Jepang) dalam sebuah manufaktur atau pabrik, atau menggunakan mesin akan digunakan huruf kanji 造る, namun jika dibuat hanya sebagai masakan rumahan maka huruf kanji yang tepat digunakan adalah 作 る. Demikian juga membuat robot akan ditulis dengan 造る,ロボットを造る namun jika membuat contoh model robot (biasanya ukuran maupun skalanya kecil), atau robot mainan anak-anak, maka diwakili 作る

Kata tsukuru dengan simbol 創 る mempunyai fitur makna menciptakan sesuatu yang baru atau yang belum ada sebelumnya. Dalam bahasa Inggris diterjemahkan menjadi create. Sebagai contoh, kaiga sakuhin wo tsukuru 'membuat lukisan' atau monogatari wo tsukuru 'membuat dongeng'. Namun demikian huruf kanji 創る karena bukan termasuk dalam Joyokanji atau huruf Kanji yang dipakai dalam komunikasi sehari-hari, sehingga tsukuru 創る jika digunakan di hadapan publik maka huruf kanji yang digunakan digantikan dengan 作 る. Sebagai polisemi, makna A, memberdayakan atau menggunakan kemampuan untuk menciptakan sesuatu yang baru, merupakan makna dasar dari verba tsukuru, kemudian makna-makna berikutnya pada poin $\mathrm{B}, \mathrm{C}$ dan seterusnya adalah makna perluasannya. Dari semua makna terdapat hubungan atau keterkaitan antara makna perluasan dengan makna dasarnya.

Copyright @2021, Kiryoku: Jurnal Studi Kejepangan, e-ISSN:2581-0960p-ISSN: 2599-0497 139 


\section{Verba Membuat}

Verba membuat dalam kalimat bahasa Indonesia, mempunyai fungsi sebagai pengisi predikat dan termasuk ke dalam verba transitif.. Kalimat transitif adalah kalimat yang predikatnya berupa verba transitif, yaitu verba yang kehadirannya membutuhkan sebuah objek penderita. Objek tersebut haruslah berupa kata yang dapat diubah menjadi subjek, apabila kalimat yangmengandung verba tersebut diubah menjadi kalimat pasif. Dalam fungsinya sebagai predikat dalam kalimat transitif bahasa Indonesia, verba membuat dapat dinyatakan dengan pola dasar kalimat sebagai S, P, O, K (subjek, predikat, objek, keterangan).

Menurut Kamus Besar bahasa Indonesia, kata membuat merupakan sebuah verba yang memiliki beberapa arti sebagai berikut:

A. Menciptakan, menjadikan, menghasilkan, membikin. Contoh:

a. Demi kepentingan mereka kami membuat suatu aturan yang baru

b. Manusia membuat berita, tetapi berita pun membentuk manusia.

B. Melakukan; mengerjakan. Contoh :

a. Harus diakui, membuat alis memang tidak mudah.

b. Terserah kepada anda bagaimana caranya membuat lukisan itu.

C. Menggunakan; memakai. Contoh :

a. Sanggupkah engkau membuat uang ini cukup untuk belanja sebulan?

b. Sebagai salah satu persiapan menjelang olimpiade tahun 2020 mendatang, Jepang telah membuat

Copyright @2021, Kiryoku: Jurnal Studi Kejepangan, e-ISSN:2581-0960p-ISSN: 2599-0497 140 suatu sistem yang dapat menanggulangi suhu ekstrim pada musim panas nanti

D. Menyebabkan; mendatangkan. Contoh :

a. Engkau membuat aku takut.

b. Masalah ekonomi, isu primordial, dan merebaknya isu buruh asing di Indonesia membuat elektabilitas Presiden Joko Widodosaat ini dinilai belum aman untuk Pemilihan Presiden (Pilpres) 2019.

\section{Persamaan dan Perbedaan}

\section{Persamaan}

Berdasarkan pemahaman terhadap makna yang terdapat di kamus, diperoleh kesimpulan bahwa persamaan kedua verba ini adalah :

A. Keduanya mempunyai makna dasar meciptakan suatu barang atau benda. Terlihat pada contoh data :

a. Karera wa ruihin wo tsukurunoga umai 'Mereka pandai membuat barang tiruan'. (ejje.weblio.jp)

b. Pembuatan vaksin corona yang sudah mencapai tahap paling jauh ada di Amerika Serikat. (kompas.com)

Dari kedua data terlihat bahwa keduanya bermakna menciptakan, membuat benda atau barang. Membuat vaksin corona atau barang tiruan, seperti pada data, keduanya memerlukan kemampuan atau keahlian dari si pembuat (subjek). Subjek mengerahkan kemampuannya untuk menghasilkan atau menciptakan vaksin corona atau barang imitasi. 
B. Keduanya mempunyai makna mendirikan bangunan, atau infrastruktur. Contoh data :

a. Sono okane wa murani atarashii hashi wo tsukurunoni yakuni tatsu. 'Uang itu berguna untuk membangun jembatan baru di desa'. (ejje. Weblio.jp)

b. Tanah merupakan elemen paling dasar dalam membuat rumah. (jateng.tribunnews.com)

Baik dalam bahasa Jepang maupun bahasa Indonesia, verba membuat bermakna mendirikan bangunan seperti gedung, rumah, maupun infrastruktur lain, jembatan, jalan, dsb. Hanya di dalam bahasa Jepang verba tsukuru yang digunakan pada makna ini ditulis dengan huruf kanji 造る dan bukan 作る untuk menyatakan membuat atau mendirikan objek yang besar.

C. Keduanya mempunyai makna memasak atau menciptakan masakan.

a. Haha wa itsumo shokuji wo tsukutte, boku wo matte ite kureta. 'Ibu selalu membuatkanku masakan dan menungguku'. (ejje.weblio.jp)

b. Mereka dapat mempraktikkan membuat kue sendiri dan menjualnya. (jateng.tribunnews.com)

Kedua data di atas menunjukkan bahwa membuat dipakai berpasangan dengan objek shokuji 'masakan', yaitu nasi lengkap dengan lauk pauknya' dan kue. Masakan dan kue pada data kalimat di atas merupakan home made, buatan rumah, dan menunjukkan aktifitas memasak, atau menghasilkan produk makanan.

D. Keduanya mempunyai makna menciptakan keadaan, kondisi, lingkungan secara sengaja. Contoh data : a. Hakubishinga

yoritsukanai

kankyou wo tsukuru. 'Menciptakan lingkungan yang tidak akan didekati musang'. (ejje.weblio.jp)

b. Ketua Komisi II mengharapkan Teten membuat lingkungan istana makin solid. (kompas.com)

Pada kedua data di atas verba membuat diikuti oleh lingkungan, yaitu ruang / tempat yang ada di sekeliling kita. Dalam data bahasa Jepang terlihat bahwa subjek (tidak disebutkan dalam kalimat) sengaja berupaya membuat lingkungan (rumah) agar tidak didekati, tidak dimasuki musang. Mungkin daerah tersebut sering ada musang yang masuk ke area rumah penduduk. Sedangkan pada kalimat bahasa Indonesia, frasa membuat lingkungan istana, berarti area atau wilayah di sekitar istana, baik secara fisik maupun orang-orang yang ada di sekitar istana. Istana dalam hal ini merujuk pada Presiden dan para pembantu pemerintah. Kedua data menyatakan makna membuat, menciptakan dengan sengaja kondisi, keadaan lingkungan sekitar agar sesuai dengan kehendak pembuat.

E. Keduanya mempunyai makna berhias.

a. Sonna kao wo shite wa ikemasen. Keshoushitsude kao wo tsukutte kinasai. 'Jangan berwajah seperti itu. Berdandanlah ke kamar rias dan kembali ke sini'. (kotowaza.jitenon.jp)

b. Menggunakan lip liner akan membuat riasan bibir seperti lipstik terlihat lebih rapi dan tahan lama. (tribunnews.com)

Verba tsukuru maupun membuat dalam bahasa Indonesia, pada data kalimat di atas menunjukkan makna berhias, berdandan, agar wajah terlihat

Copyright @2021, Kiryoku: Jurnal Studi Kejepangan, e-ISSN:2581-0960p-ISSN: 2599-0497 141 
Tersedia online di http://ejournal.undip.ac.id/index.php/kiryoku

cantik. Pada data bahasa Jepang kao wo tsukuru 'membuat wajah' merupakan bentuk idiom / kanyouku yang mempunyai makna berdandan, merias wajah. Pada data a, kao wo tsukuru bersinonim dengan kao wo koshiraeru, dan bisa saling bersubstitusi. Selain itu kao wo tsukuru juga bisa bermakna, (dengan sengaja) membuat ekspresi wajah, seperti pada data kalimat berikut :

Kanojo wa kimochi towa urahara ni nyuuwana kao wo tsukutte, okyakusamani outaishiteita.

'Bertentangan dengan perasaannya, Dia (perempuan) membuat wajah penuh kelembutan dan menanggapi parapelanggannya.

(kotowaza.jitenon.com)

\section{Perbedaan}

Selain persamaan ditemukan juga perbedaan makna membuat dalam bahasa Jepang dan bahasa Indonesia yang terdapat pada :

\section{A. Verba bahasa Indonesia membuat, mempunyai makna menyebabkan, mendatangkan. Contoh data :}

a. Pandemi ini membuat semua serba sulit. (kompas.com)

b. Kontrak baru itu membuat Antetokounmpo batal berstatus free agent pada musim depan. (cnnindonesia.com)

Verba membuat pada 2 contoh data kalimat a dan b bermakna menyebabkan atau menjadi penyebab. Kondisi pandemic menyebabkan semua menjadi sulit. Sementara pada data $b$, menunjukkan hilangnya status seseorang akibat adanya kontrak baru.
B. Verba
bahasa
Indonesia membuat mempunyai makna

menggunakan atau melakukan kesepakatan, perjanjian. Contoh data :

a. Saya membuat kesepakatan dengan orang tua agar mereka mau membelikan buku bacaan yang disukai anak-anaknya. (kompas.com)

Dalam bahasa Indonesia, verba membuat dapat diikuti oleh objek kesepakatan, janji, namun dalam bahasa Jepang terdapat frasa keiyaku wo suru, appoint wo toru, yakusoku wo suru, menggunakan verba suru dan tidak menggunakan verba tsukuru karena tidak mempunyai fitur makna menciptakan atau membuat sesuatu yang baru.

C. Verba tsukuru dalam bahasa Jepang mempunyai makna memelihara dengan objek tanaman yang bisa dibudidayakan dan diambil manfaatnya. Contoh data :

a. Niwa de daikon, tomato, sukini toitta yasai wo tsukutteimasu. 'Di halaman saya menanam sayuran lobak, tomat dan timun'. (ejje.weblio.com)

Contoh lain makna memelihara, membudidayakan seperti pada okome wo tsukuru ', hana wo tsukuru, hata wo tsukuru. Semua frasa ini menyatakan makna mengolah tanahnya, merawat tanaman tersebut untuk kemudian diambil hasilnya baik padi, sayuran, bunga dsb. Makna ini mempunyai kaitan dengan makna dasarnya yaitu menciptakan (yang sebelumnya tidak ada).

D. Verba tsukuru dalam bahasa Jepang mempunyai makna merawat, mendidik orang. Contoh data :

a. Robotto kontesuto : mono zukuri wa hito zukuri. 'Kontes robot : menciptakan barang adalah menciptakan manusia (Minna chukyu 2) 
Terjemahan hitozukuri secara leksikal dalam bahasa Indonesia adalah membuat orang. Hito zukuri bermakna membuat kepribadian, karakter seseorang menjadi lebih baik, atau mendidik. Melalui kontes membuat robot diharapkan bukan hanya membuat peserta pintar menciptakan barang (robot) tetapi juga membentuk / mendidik orang (pembuatnya) untuk mempunyai daya kreatifitas, jiwa sportif dan membentuk karakter lain melalui kontes tersebut. Makna mendidik tidak ditemukan dalam verba bahasa Indonesia membuat.

\section{SIMPULAN}

Berdasarkan pembahasan yang telah dilakukan sebelumnya maka dapat diambil kesimpulan bahwa verba tsukuru dalam bahasa Jepang dan verba membuat dalam bahasa Indonesia banyak mempunyai kesamaan makna, namun demikian juga memiliki perbedaan-perbedaan, masing-masing memiliki fitur makna tersendiri.

Verba tsukuru dalam bahasa Jepang diwakili oleh tiga huruf kanji,

A. Tsukuru dengan penulisan 作 る, merupakan yang paling umum, digunakan untuk menyebutkan objek konkrit maupun abstrak, benda berukuran kecil atau berskala kecil, dan menggunakan tangan bukan mesin.

B. Tsukuru dengan penulisan 造 るdigunakan untuk membuat objek berukuran besar seperti bangunan, produk yang dihasilkan di pabrik, membuat menggunakan mesin.
C. Tsukuru dengan penulisan 創
る、 seringkali
penulisannya

digantikan dengan symbol 作る, karena huruf ini tidak lazim digunakan dalam komunikasi seharihari. Mempunyai fitur makna menghasilkan sesuatu yang baru, menciptakan sesuatu yang sebelumnya tidak ada. Terutama untuk ide, pemikiran konsep baru. Juga digunakan untuk menciptakan hasil karya seni seperti lagu, puisi dsb.

Makna dasar kedua verba polisemi ini sama, yaitu menciptakan benda baik konkrit maupun abstrak dengan menggunakan kemampuan yang dimiliki. Membuat bangunan, masakan, menghias adalah fitur makna yang sama. Namun makna menyebabkan dalam verba membuat tidak ditemukan dalam bahasa Jepang. Sebaliknya makna memelihara, merawat, mendidik, dalam bahasa Jepang tidak ditemukan pada makna membuat di Bahasa Indonesia. Selain itu membuat kesepakatan, perjanjian juga tidak menggunakan verba tsukuru, sedangkan dalam bahasa Indonesia menggunakan verba membuat.

Sebagai turunan dari verba tsukuru masih terdapat verba lain yang merupakan verba majemuk seperti tsukuridasu, tsukuriageru, tsukurikaeru, dan lainnya yang tidak termasuk dalam pembahasan ini.

\section{DAFTAR PUSTAKA}

Isihwata, Toshio dan Takada Makoto. 1995. Taishou Gnegogaku. Tokyo: Taishuukan SHoten Co., Ltd

Keraf, Gorys. 1991. Tata Bahasa Rujukan Bahasa Indonesia. Jakarta: Grasindo.

Mahsun, M.S. 2006. Metode Penelitian Bahasa: Tahapan Strategi, 
Metode, dan Tekniknya.

Jakarta: Raja Grafindo Persada

Miharu, Akimoto. (2002). Yoku Wakaru

Goi. Tokyo: Aruku

Moeliono, Anton M. (1988). Kamus Besar

Bahasa Indonesia. Jakarta:

Balai Pustaka

Puspita, Renny. 2013. Analisis Vebra

Tsukuru dalam Bahasa Jepang.

Skripsi, S 1.

Senichi, Hisamatsu. (1985). Kadokawa

Kokugo Jiten. Tokyo :

Kadokawa Shoten

Shinmura, Izuru. (1998). Koujien. Tokyo: Iwanami Shoten.

Sutedi, Dedi. 2003. Dasar-Dasar Linguistik

Bahasa Jepang. Bandung:

Humaniora.

Tarigan, Henry Guntur 1992. Pengajaran Analisis Kontrastif Bahasa.

Bandung: Angkasa

Tim Penyusun Kamus Pusat Bahasa. 2001.

Kamus Besar Bahasa

Indonesia. Jakarta:

Departemen Pendidikan

Nasional.

Referensi website

www.cnnindonesia.com

$\underline{\text { www.ejie.weblio.jp }}$

www.joglosemarnews

www.kompas.com 